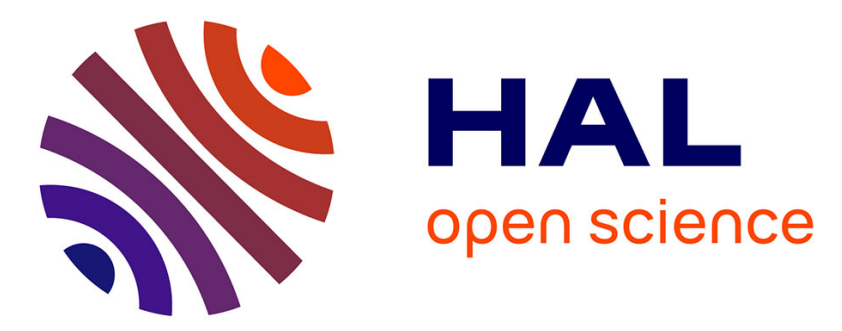

\title{
On mirror temperature of a semiconductor diode laser studied with a photothermal deflection method
}

\author{
M. Bertolotti, G. Liakhou, R. Li Voti, R. Wang, C. Sibilia, A. Syrbu, V.
}

Yakovlev

\section{- To cite this version:}

M. Bertolotti, G. Liakhou, R. Li Voti, R. Wang, C. Sibilia, et al.. On mirror temperature of a semiconductor diode laser studied with a photothermal deflection method. Journal de Physique IV Proceedings, 1994, 04 (C7), pp.C7-211-C7-214. 10.1051/jp4:1994751 • jpa-00253280

\section{HAL Id: jpa-00253280 https://hal.science/jpa-00253280}

Submitted on 1 Jan 1994

HAL is a multi-disciplinary open access archive for the deposit and dissemination of scientific research documents, whether they are published or not. The documents may come from teaching and research institutions in France or abroad, or from public or private research centers.
L'archive ouverte pluridisciplinaire HAL, est destinée au dépôt et à la diffusion de documents scientifiques de niveau recherche, publiés ou non, émanant des établissements d'enseignement et de recherche français ou étrangers, des laboratoires publics ou privés. 


\title{
On mirror temperature of a semiconductor diode laser studied with a photothermal deflection method
}

M. Bertolotti, G. Liakhou*, R. Li Voti, R.P. Wang**, C. Sibilia, A.V. Syrbu* and V.P. Yakovlev*

Dipartimento di Energetica, Università di Roma "La Sapienza", Via Scarpa 16, 00161 Roma, Italy

* Technical University of Moldova, Stephan Cel Mare 168, 277012 Kishinev, Moldova

** Department of Physics, Peking University, Beijing 100871, China

\begin{abstract}
The mirror temperature response of a diode laser to injection current is studied through the photodeflection method. A theoretical model is presented together with some experimental measurements for a AlGaAs quantum well laser diode.
\end{abstract}

\section{INTRODUCTION}

The study of the degradation due to the heating process is of great importance in the field of semiconductor lasers 1,2 . Therefore the knowledge of the rise temperature of both active zone and mirrors, as a function of the laser diode injection current, become fundamental for the planning and fabrication processes and applications.

In the present paper a new method to measure the mirrors' rise temperature is suggested in alternative to other methods The present method, based on the photothermal deflection technique ("mirage effect") 3 is applied to AIGaAs diode laser samples, prepared as described in ref. 4 .

\section{THEORETICAL CONSIDERATION}

A new application of the well-known "mirage effect" is proposed to determine the mirrors' temperature rise $\left(T_{\mathrm{m}}\right)$ and its behaviour as a function of laser diode drive current. The "mirage technique"3 $(P D)$ is usually applied to material slabs by heating the sample in a region far from the border with respect to the thermal diffusion length 
$\ell(\ell=\sqrt{2 \mathrm{D} / \omega})$ where $\mathrm{D}$ is the sample thermal diffusivity and $\omega$ the angular pump beam modulation frequency), so to neglect edge effects.

In the present paper the theory has been modified for the case of a finite dimension sample, with the heating source in an asymmetric position very close to one edge of the laser diode (see Fig.1). The drive current, modulated at an angular frequency $\omega$, is assumed to be homogeneously distributed along the laser cavity and produces the heat quantity q per unit time and per unit length of the cavity, into the active region which plays the role of the heat source. Beside the heat quantity $q$, we could introduce a source equivalent temperature $T_{q}$ defined as $T_{q}=q / k$ where $k$ is the sample thermal conductivity.

The consequence, as will be clear after, is that the temperature $T_{q}$ could be directly obtained with a photothermal deflection experimentum, giving also an idea of the bulk average temperature rise.

The temperature distribution is obtained by solving the heat Fourier equations together with the boundary conditions for the geometry of fig.1. Some simplification can be made neglecting the thermal flux in air with respect to the thermal flux going into the copper heat sink. The temperature rise in both bulk and active region is given by 4

$$
\mathrm{T}=\frac{\mathrm{T}_{q}}{w}\left[\frac{\sinh (\beta \mathrm{y})}{\beta \cosh (\beta \mathrm{h})}+\frac{4}{p a} \sum_{\mathrm{n}=1}^{\infty} \frac{\sinh \left(\beta_{\mathrm{n}} \mathrm{y}\right) \cos (\mathrm{npx}) \sin \left(\frac{\mathrm{npa}}{2}\right)}{n \beta_{\mathrm{n}} \cosh \left(\beta_{\mathrm{n}} \mathrm{h}\right)}\right] e^{j \mathrm{jox}}\left\{\begin{array}{l}
0<z<L \\
-\frac{w}{2}<x<\frac{w}{2} \\
0<y<h
\end{array}\right.
$$

where $a, w, h$ are the dimensions specified in fig. $1, \beta^{2}=\frac{j \omega}{D}, p$ is the fundamental spatial frequency given by $\mathrm{p}=\frac{2 \pi}{\mathrm{w}}$ and $\beta_{\mathrm{n}}=\sqrt{\beta^{2}+(\mathrm{np})^{2}}$.

By a careful inspection of eq.(1), the maximum of the rise temperature is reached in the d.c. case in the active region just at the semiconductor laser mirror, playing a critical role in the degradation of the device. In a typical laser the bulk height $(h \cong 120 \mu \mathrm{m})$ and the bulk width $(w \cong 400 \mu \mathrm{m})$ are of the same order, while the strip width $(a \cong 10 \mu \mathrm{m})$ is much shorter, so that some simplifications can be made using eq.(1) in the calculation of the mirror rise temperature $T_{m}{ }^{4}$

$\frac{T_{m}}{T_{a}}=\frac{h}{w}+\frac{w}{a \pi^{2}} \sum_{n=1}^{\infty} \frac{\tanh \left(2 n \pi \frac{h}{w}\right) \sin \left(n \pi \frac{a}{w}\right)}{n^{2}} \stackrel{2 \pi \stackrel{h}{w}>1, \frac{a}{w} \ll 1}{\longrightarrow} \cong \frac{1}{\pi}+\frac{h}{w}+\frac{\ln \left[\frac{w}{\pi a}\right]}{\pi}$.

When a probe laser beam travels along the $x$ direction, in the air layer very close to the bulk (see Fig.1), due to the thermal gradients, an angular deflection both in $y$ and in $z$ direction is expected. The photodeflection theory ${ }^{3}$, applied to the thermal distribution 
given by Eq.(1), after some semplifications assuming to operate at high drive current frequency $(\ell<h)$, gives for both amplitude and phase of the lateral component of the deflection angle $\phi_{y}$ the following expression:

$$
\left\{\begin{array}{c}
\left|\phi_{y}(y)\right|=\frac{T_{q}}{n_{a}}\left|\frac{d n_{a}}{d T}\right| \exp \left[\frac{y-h}{\ell}\right] \\
\vartheta(y)=\frac{y-h}{\ell}
\end{array}\right.
$$

where $\left|\phi_{y}(y)\right|, \vartheta(y)$ respectively are the amplitude and phase of the lateral deflection angle as a function of the offset $y, \frac{\mathrm{dn}_{\mathrm{a}}}{\mathrm{dT}} \equiv-10^{-6} \mathrm{~K}$ is the air optothermal coefficient, $\mathrm{n}_{\mathrm{a}} \cong 1$ is the air refractive index. Note that both the phase and the logarithm of amplitude have the same linear behaviour with $y$, from which $\ell$ and consequently $D$ are worked out. In priciple an easy way to calculate $\mathrm{T}_{\mathrm{q}}$ should be by measuring the amplitude at the edge, close to the active region, according with eq.(3) and after some algebra $\left[\mathrm{T}_{\mathrm{q}}=\left|\Phi_{\mathrm{y}}(\mathrm{y}=\mathrm{h})\right| \cdot 10^{6} \quad\left({ }^{\circ} \mathrm{K}\right)\right]$, but in practice, due to the probe beam finite size ( $\cong 15 \mu \mathrm{m}$ ), the amplitude in $y=h$ is far away from the value expected in eq.(3) and an extrapolation of data is in general needed

\section{EXPERIMENTAL DATA}

The experimental values of both $\ln \left|\Phi_{y}\right|$ and phase $\vartheta(y)$ as a function of $y / h$, for a single-quantum-well AIGaAs/GaAs laser diode 4 have been plotted, for three different frequencies $(40 \mathrm{KHz}-62.5 \mathrm{KHz}-90 \mathrm{KHz}$ ), and for a lasing current of $70 \mathrm{~mA}$ ( see Figs.2). Extrapolated data (see curves $a, b$ and $c$ in fig.2a) in $y=h$, give the source temperature value $\mathrm{T}_{\mathrm{q}}=57 \pm 8^{\circ} \mathrm{K}$. Knowing the geometrical dimensions of the laser and by using eq.(2), the mirror rise temperature $T_{m}=80 \pm 12^{\circ} \mathrm{K}$ is finally found. The values of the thermal diffusion length for the different frequencies have also been derived from the linear slopes and a bulk thermal diffusivity $D=0.28 \pm 0.01 \mathrm{~cm} / \mathrm{s}$ is obtained. The calculated value of $\mathrm{D}$, which for a quantum-well laser diode has to be considered as an average between the thermal diffusivities of AlGaAs and GaAs, is in good agreement with the values found in literature.

\section{CONCLUSIONS}

In the present paper, a method is given for determining the quantity of heat generated by the injection current in the active region of a semiconductor laser by using the 
photothermal deflection technique, and the results of the theoretical study on temperature rise distribution in the laser diode. The photothermal deflection method allows to determine also the thermal diffusivity of the semiconductor laser diode.

\section{REFERENCES}

1- W.C.Tang, H.J.Rosen, P.Vettiger and D.J.Webb - Appl.Phys.Lett. 59 (1991) 10051007.

2- H.Brugger and P.W.Epperlein - Appl.Phys.Lett.56 (1990) 1049-1052.

3- W.B.Jackson, N.M.Amer, A.C.Boccara and D.Fournier - Appl. Optics 20 (1981) 1333-1344

4- M.Bertolotti, G. Liakhou , R. Li Voti, R.P.Wang, C. Sibilia, V.P.Yakovlev Journ.Appl.Phys 74 (1993) 7054-7060.

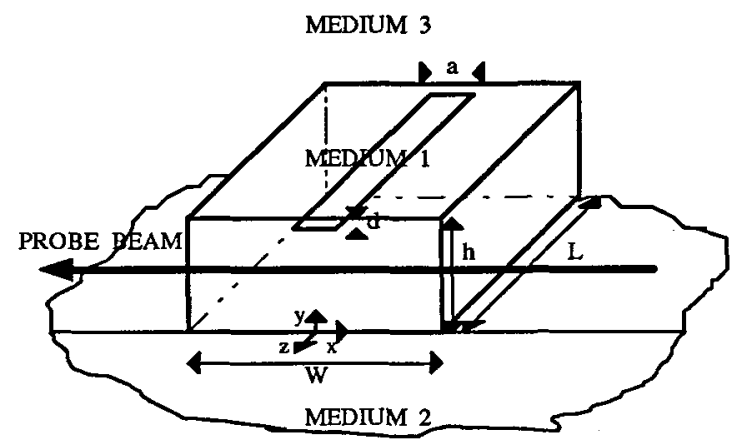

Fig.1 - Scheme of the configuration

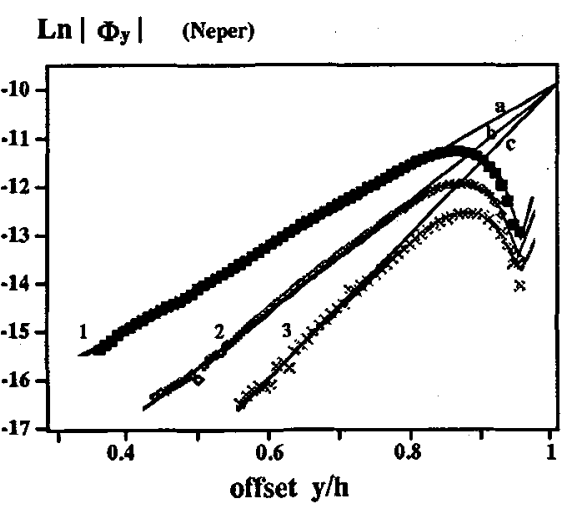

2a)

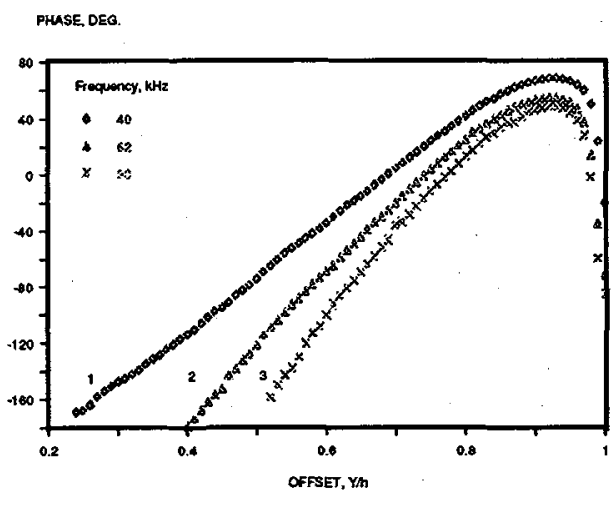

2b)

Figs.2 . Experimental results for different frequencies (1) $40 \mathrm{KHz}-$ (2) $62.5 \mathrm{KHz}-$ (3) $90 \mathrm{KHz}$, and for a lasing current of $70 \mathrm{~mA}$. 2a) logarithm of amplitude , 2b) phase. 